\title{
Análise dos impactos do processo de implantação da ISO 9001/2008 em empresas prestadoras de serviços em limpeza e manutenção predial
}

Este estudo objetiva analisar os impactos gerados no processo de implantação da norma International Organization for Standardization (ISO) 9001:2008 em empresas prestadoras de serviços em limpeza e manutenção predial. Foram analisados outros estudos já publicados nas plataformas acadêmicas, para que fosse detectada as reações dos colaboradores e empregadores no processo da gestão da qualidade. 0 método de pesquisa utilizado foi a bibliográfica, destacando-se as leituras de artigos, revistas especialistas no assunto abordado, sites e livros. A verificação das ações dos colaboradores diante das mudanças dos processos organizacionais, faz com que esse trabalho seja de tamanha relevância, pois relata as reações internas e externas das organizações em se conscientizar da importância de aquisição de uma certificação de qualidade, como meio de diferencial diante do cenário mercadológico competitivo.

Palavras-chave: ISO 9001:2008; Qualidade; Impacto; Organizações.

\section{Analysis of the impacts of the implementation process of ISO 9001/2008 on companies providing services in cleaning and building maintenance}

\begin{abstract}
This study aims to analyze the impacts generated in the deployment process of the standard International Organization for Standardization (ISO) 9001:2008 on contractors in cleaning and building maintenance. We analyzed other studies already published academic platforms, to be detected the reactions of employees and employers in the process of quality management. The research method used was the essay, especially the readings of articles, subject experts, magazines websites and books. The verification of the actions of the employees on the changes of organizational processes, makes this work is of such relevance, because reports internal and external reactions in organisations aware of the importance of certification acquisition quality, as a means of competitive market scenario in front of the differential.
\end{abstract}

Keywords: 9001:2008 ISO; Quality; Impact; Organizations.

Topic: Planejamento, Estratégia e Competitividade

Reviewed anonymously in the process of blind peer.
Received: 06/07/2017

Approved: 11/12/2017

Leandro Costa dos Santos

Faculdade Uninassau de Aracaju, Brasil

http://lattes.cnpq.br/6797810702322741

leandrocosta1989@gmail.com

Helena Maria Fagundes dos Santos Braz Faculdade Uninassau de Aracaju, Brasil http://lattes.cnpq.br/9373582225272500 hbraz81@gmail.com

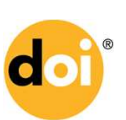

DOI: 10.6008/SPC2595-4318.2017.001.0002
Referencing this:

SANTOS, L. C.; BRAZ, H. M. F. S.. Análise dos impactos do processo de implantação da ISO 9001/2008 em empresas prestadoras de serviços em limpeza e manutenção predial. Entrepreneurship, v.1, n.1, p.1727, 2017. DOI: http://doi.org/10.6008/SPC2595-4318.2017.001.0002 


\section{INTRODUÇÃO}

A certificação da ISO 9001/2008 no mundo, foi elaborada a partir dos dados da última da pesquisa ISO (2011) e apontam que são mais de um milhão de organizações certificadas em exatos 184 países. Desde 1993, ano da primeira pesquisa, até 2012 sua última edição foi evidenciado o crescimento das empresas. Em 1993 eram menos de 50 mil certificados emitidos em 60 países e em 2012 foram mais de 1,1 milhão de certificados emitidos em 184 países.

Embora o Brasil apareça entre os dez países com maior número de certificados, há de se considerar que no Brasil há 5,1 milhões de empresas no Cadastro Central de Empresas (CEMPRE) do IBGE (2011), portanto, os quase trinta mil certificados ISO 9001/2008 existentes no Brasil, representa 0,58\% do total de empresas existentes, sendo um percentual pequeno.

A cada dia que passa as organizações estão se preocupando em ofertar seus serviços no momento certo, no lugar certo, na hora certa, a um preço acessível a todos e com qualidade. Diante do exposto, fica nítido que a preocupação com a excelência nos processos se torna algo cada vez mais a ser atingido. As empresas prestadoras de serviços de manutenção em limpeza predial, buscam ter um destaque maior na qualidade, uma vez que a concorrência entre as mesmas é grande.

Convém que a adoção de um sistema de gestão da qualidade seja uma decisão estratégica de uma organização. $O$ projeto e a implementação de um sistema de gestão da qualidade de uma organização são influenciados por: Seu ambiente organizacional, mudanças neste ambiente e os riscos associados com este ambiente, suas necessidades que se alteram, seus objetivos particulares, os produtos fornecidos, os processos utilizados e seu porte e estrutura organizacional (ISO:9001, 2008).

A gestão de pessoas nesta área de operação é algo bastante complexo, pois cada um tem um pensamento e quase sempre querem executar os seus serviços da melhor forma que lhe convirem. É neste momento que surge a demanda de padronização dos processos internos e externos das organizações. A qualidade de uma aquisição de serviços só poderá ser vista após a execução do mesmo e em momento algum a mesma será alcançada se a empresa trabalhar com várias formas de execução.

Quando todos os colaboradores participam de forma efetiva dos processos de auditoria de implantação, os resultados são os melhores possíveis, tais como: mudança e aumento da cultura de compromisso, desenvolvimento e responsabilidade nas questões relacionadas a qualidade total dos serviços.

A organização de uma empresa consiste em sua estrutura, suas políticas e sua cultura corporativa, que podem se tornar disfuncionais em um ambiente de negócios em rápida transformação. Enquanto a estrutura e as políticas podem ser alteradas (ainda que com dificuldade), a cultura da empresa é quase impossível de ser mudada. Muitas vezes, porém, mudar a cultura corporativa é a chave para implementar uma estratégia de sucesso (KOTLER; KELLER, 2012).

Portanto, o ponto norteador deste estudo científico se dá em uma indagação: ISO 9001/2008: Análise dos impactos do processo de implantação em empresas prestadoras de serviços em limpeza e manutenção predial. Dentre os objetivos desta pesquisa pode-se destacar: (a) Identificar as principais mudanças no comportamento organizacional das empresas; (b) Descrever o passo a passo da implementação da ISO: 
9001:2008; (c) Verificar a reação dos colaboradores diante a mudança dos processos internos e externos; (d) Relatar os motivos de uma organização se conscientizar da importância de adquirir uma certificação.

A empresa tendo um sistema de gestão da qualidade implantado nos seus processos internos e externos, faz com que os clientes tenham confiança e credibilidade nos serviços prestados e que também se atentem ao tipo de fornecedor que entra na organização. A certificação chega para abrir portas na organização e faz com que a mesma cresça de forma acentuada e constante, onde cada vez mais a sua participação nos mercados vai crescendo, devido a excelência no que é oferecido aos seus clientes.

A implantação da ISO 9001:2008, faz com que a organização tenha capacidade de exportar seus produtos ou serviços, uma vez que muitos países a fora exigem determinadas certificações específicas para poderem contratar. Isso faz com que a busca pela melhoria contínua se torne cada vez mais crucial, pois em um ambiente de tantas tecnologias e métodos científicos, o empirismo fica acuado e sem espaço, ou seja, só ficarão no mercado os melhores.

\section{METODOLOGIA}

O referente artigo científico tem como principal objetivo a realização de pesquisa bibliográfica através de sites, revistas e artigos para verificar os impactos do processo de implantação da ISO 9001:2008 em empresas prestadoras de serviços em limpeza e manutenção predial.

Esta metodologia foi escolhida devido a gama de assuntos disponíveis e pertinentes ao que está sendo abordado neste trabalho e pela facilidade em pesquisar as informações necessárias, sem ter barreiras físicas ou humanas que impeça o bom andamento da pesquisa.

Para Vergara (2011), a utilização e adoção de normas e métodos são essenciais para conferir a confiabilidade e o rigor necessários a esse tipo de trabalho. Assim, faz-se necessário informar ao leitor o tipo de pesquisa que será realizada, descrevendo-se sua conceituação e justificativa concernente à investigação específica.

\section{DISCUSSÃO TEÓRICA}

\section{A Gestão da Qualidade}

Conseguir alcançar, aperfeiçoar e manter a competitividade no mercado brasileiro e internacional depende de fornecimento de alta qualidade, produtos e serviços de baixo custo e no mínimo tempo possível (AL-RAWAHI et al., 2011).

A gestão da qualidade deve ser encarada como um investimento de retorno a médio e longo prazo, que poderão destacar a organização de tal forma, onde o público consumidor irá divulgar a qualidade da marca de forma espontânea. Tudo isso, faz com que perda financeiras pela falta de procedimentos nos processos organizacionais não venham a acometer a organização.

Sendo assim, do ponto de vista financeiro, é melhor ter custos com qualidade e posteriormente não incorrer em custos mais elevados que poderiam acontecer com a ausência da mesma. Concordando com 
Zacharias (2009), Lélis (2012) opina-se que é possível comparar os gastos da empresa com qualidade aos custos que ela teria sem adoção de um programa de gestão da qualidade. Em algumas situações, o cálculo evidencia que a situação pode piorar se a organização não adotar um programa de gestão da qualidade.

É importante ressaltar uma filosofia do Japão - país onde foram dados os primeiros passos da gestão da qualidade - Kaizen, que preconiza um sistema contínuo de aprimoramento nas organizações, onde todos os funcionários - alta administração, gerentes e operários - devem se envolver com o desenvolvimento e a melhoria contínua.

Um importante conceito da gestão da qualidade total, idealizado por Deming (1982), é o ciclo PDCA: P significa (plan), D quer dizer do (fazer), C significa control (controlar) e A, action (ação). Esse mecanismo prega que todos os processos devem ser continuamente estudados e planejados (inclusive modificações e melhorias), ter suas mudanças implementadas e controladas (medição e observação dos efeitos) e, depois desses passos, deve-se realizar uma avaliação dos resultados obtidos.

\section{A Qualidade a Nível Universal}

É sabido de todos mundialmente falando, que vivemos em prol de termos sempre o melhor, no menor preço e com alto grau de qualidade, por isso a certificação ISO 9001/2008, é uma norma internacional, onde a sua sigla significa: International Organization for Standardization, criada em 1946 após final do conflito internacional, representantes de 25 países reuniram-se em Londres e decidiram criar uma nova organização, para padronização, com o objetivo de "facilitar a coordenação internacional e unificação dos padrões industriais".

Esta organização internacional trata-se de uma entidade não governamental, essa nova organização iniciou suas atividades oficialmente em 23 de fevereiro de 1947 com sede em Genebra, na Suíça, hoje presente em cerca de 161 países, no Brasil a mesma é representada pela ABNT "Associação Brasileira de Normas Técnicas".

A sigla "ISO" foi originada da palavra isonomia, sinônimo de igualdade, cujo objetivo é a padronização do gerenciamento do sistema da qualidade visando a sua unificação de forma universal. A sua função é a de promover a normatização de produtos e serviços, para que a qualidade dos mesmos seja permanentemente melhorada.

\section{Questão da Qualidade na Prestação de Serviços}

Os conceitos de qualidade no decorrer dos anos, de acordo com Carvalho et al. (2012) afirma que a qualidade é um conceito muito dinâmico, uma percepção que trabalha com direcionamentos que sofrem mudanças ao longo de períodos diferentes, às vezes de maneira muito profunda.

Qualidade não deve ser entendida de forma passional ou amadora, mas de forma técnica e quantitativa, porque é um dos mais importantes aspectos na gestão comercial, econômica e financeira de uma organização. Se a qualidade tem custo, a não qualidade também tem; Por isso, faz-se necessário quantificar estes dois custos para se determinar o ponto de otimização do resultado financeiro da empresa (ZACHARIAS, 2009). 
Toda esta preocupação, visa o ponto maior de todo o comércio existir: Os clientes. A satisfação dos mesmos, é crucial para que todo negócio dê certo. Quando a organização consegue ser transparente, honesta, fiel a qualidade dos produtos ou serviços prestados, a mesma começa a ter o seu espaço de forma mais sólida do que os seus concorrentes, e isso faz de a mesma ter vontade de expandir suas fronteiras de negócios.

Para Santos (2007), a qualidade visa a atender às reais necessidades dos clientes de maneira a assegurar sua satisfação e consequentemente fidelização a produtos e serviços, anunciados de maneira positiva e recomendando-os a outras pessoas.

\section{Conceito de Qualidade}

O quadro 01 relata o pensamento de cada autor sobre a definição de qualidade, com a definição de cada um de acordo com o tempo em que o conceito foi criado. Existe pequenas divergências nos conceitos de cada um.

Quadro 01: Definição da qualidade.

\begin{tabular}{|l|l|l|}
\hline ANO & AUTOR & DEFINIÇÃO \\
\hline 1949 & Ishikawa & $\begin{array}{l}\text { Rápida percepção e satisfação das necessidades do mercado, adequação ao uso dos produtos e } \\
\text { homogeneidade dos resultados do processo (baixa variabilidade). }\end{array}$ \\
\hline 1951 & Fiegenbaum & $\begin{array}{l}\text { Qualidade é uma maneira de se gerenciar os negócios da empresa. Aprimoramento da qualidade só pode } \\
\text { ser alcançado em uma empresa com a participação de todos. Perfeita satisfação do usuário. }\end{array}$ \\
\hline 1954 & Juran & Qualidade é a adequação ao uso. Satisfação das aspirações do usuário. \\
\hline 1979 & Crosby & Qualidade é conformidade com especificações, com os requisitos do cliente. \\
\hline 1998 & Kotler & $\begin{array}{l}\text { Qualidade é a soma dos aspectos e características de um serviço ou produto que conseguem } \\
\text { proporcionar a satisfação do cliente. }\end{array}$ \\
\hline 2006 & Paladini & $\begin{array}{l}\text { Qualidade é uma palavra que tem apresentação de características que demonstram dificuldades para } \\
\text { estabelecimento de uma perfeita definição. Não é possível considerá-la um termo de característica } \\
\text { exclusiva e única. }\end{array}$ \\
\hline
\end{tabular}

Fonte: Adaptado de Santos (2007).

De acordo com o Dicionário Michaelis, a palavra "qualidade" deriva do latim qualitate e significa atributo, condição natural ou propriedade pela qual algo ou alguém se individualiza, distinguindo-se dos demais. A palavra também pode expressar o grau de perfeição, precisão ou conformidade a certo padrão. Em outras palavras, como afirma o dicionário Aurélio, é a maneira de ser de algo ou alguém, sua superioridade ou excelência. "A maioria das pessoas concorda que qualidade é aquilo que produz satisfação, que está relacionada a um preço justo, a um produto que funciona corretamente e a um serviço prestado de forma a superar as expectativas de quem dela faz uso" (VERGUEIRO, 2002).

Quadro 02: Pressupostos das eras da qualidade.

\begin{tabular}{|c|c|c|c|}
\hline 1a Era: Inspeção & $\begin{array}{c}\text { 2a Era: Controle da } \\
\text { Qualidade }\end{array}$ & 3a Era: Garantia da Qualidade & $\begin{array}{l}\text { 4a Era: Administração da Qualidade } \\
\text { Total }\end{array}$ \\
\hline $\begin{array}{l}\text { Eliminação de } \\
\text { erros; } \\
\text { Retificação. }\end{array}$ & $\begin{array}{l}\text { Métodos estatísticos; } \\
\text { Desempenho do processo; } \\
\text { Padrões de qualidade. }\end{array}$ & $\begin{array}{l}\text { Sistemas de qualidade; Custo de } \\
\text { qualidade; Solução de problemas; } \\
\text { Planejamento da qualidade. }\end{array}$ & $\begin{array}{l}\text { Envolve toda a operação; Estratégia da } \\
\text { qualidade; Empowerment dos } \\
\text { empregados; Envolve consumidores. }\end{array}$ \\
\hline
\end{tabular}

Fonte: Barçante (1998 citado por BUENO, 2002). 


\section{Abordagem nos Processos Organizacionais e nos Sistemas de Gestão da Qualidade}

Os processos que toda organização empresarial seja ela prestadora de serviços ou vendas de materiais, deverão realizar a seleção dos processos que serão auditados, a fim de evitar quaisquer discrepâncias nos setores da organização. A norma da gestão da qualidade promove não só a padronização e gestão dos processos internos ou externos, mas também verifica o nível da qualidade que está sendo gerada, pois a eficácia é sempre a meta a ser batida.

Para uma organização funcionar de maneira eficaz, ela tem que determinar e gerenciar diversas atividades interligadas. Uma atividade ou conjunto de atividades que usa recursos e que é gerenciada, de forma a possibilitar a transformação de entradas em saídas pode ser considerada um processo. Frequentemente a saída de um processo é a entrada para o processo seguinte. (ISO 9001:2008).

O Sistema de Gestão da Qualidade (SGQ) é definido segundo a NBR ISO 9000 como um conjunto de elementos inter-relacionados ou interativos para estabelecer política, objetivos, para atingir estes objetivos e para dirigir e controlar uma organização (entendida como grupo de instalações e pessoas com um conjunto de responsabilidades, autoridades e relações) no que diz respeito à qualidade, que é o grau no qual um conjunto de características inerentes ao produto ou prestação de serviço satisfaz a requisitos, que são necessidades ou expectativas, expressos pelo cliente de forma implícita ou obrigatória.

\section{Mudanças no Comportamento Organizacional das Empresas}

As organizações que se aderem ao sistema de gestão da qualidade nos seus processos, tem uma mudança de comportamento organizacional de forma rápida, pois começam a enxergar o sistema de negócio de forma holística, se preocupando com fatores que antes eram considerados desprezíveis.

A mudança de mentalidade dos cidadãos está fazendo as empresas mudarem de dentro para fora, muito mais rapidamente do que ocorria anteriormente ou do que a imaginação alcançava. Os modos de gestão atualmente são outros e vão sendo modificados. 0 processo administrativo mudou e as organizações passam a se preocupar com os produtos, serviços, desempenho em todos os seus setores, a redução de custos, eliminação de desperdícios, diminuição de prazos, produtividade e cada vez mais com o atendimento a clientes, considerando a satisfação do consumidor a maior meta. (OLIVEIRA, 2012).

Todos os fatores de mudanças que ocorrem nas empresas, causam uma série de questionamentos, em saber se o público-alvo está compreendendo e visualizando as mudanças da aderência a implantação do processo da ISO 9001/2008, com isso a preocupação de sempre oferecer o melhor para que as expectativas sejam sempre superadas.

Em cenário de crise econômica, as empresas estão procurando mudanças positivas para poderem se sustentar no meio da concorrência, e dentre estas mudanças, encontra-se a adoção de medidas de diferenciação na gestão da qualidade dos seus processos. A partir deste ponto, as atitudes começam a surtirem efeitos, pois o público interno e externo começa a ter afinidade com a importância da qualidade total nos processos organizacionais.

Estas mudanças citadas acima podem serem evidenciadas em várias referências bibliográficas clássicas sobre o assunto, como por exemplo o histórico da qualidade ao longo dos séculos, Tenner et al. 
(1992), que evidenciam transformações na forma de entende-la, e Deming (1990), que avalia transformações nos processos produtivos sob a motivação da qualidade (PALADINI PACHECO, 2009).

Reação dos colaboradores diante a mudança dos processos internos e externos.

Quando os processos internos e externos de uma organização, passam por mudanças de aperfeiçoamento, os colaboradores levam um certo tempo para começarem a utilizar a os processos padronizados que foram adotados, por isso a grande a importância do envolvimento pleno de todos, para que o investimento tenha o resultado esperado pelos gestores.

O mundo dos negócios está mudando e para sobreviver a empresa precisa romper barreiras a fim de garantir a permanência do seu negócio num mercado que tende a ser cada vez mais competitivo. "A forma pela qual as organizações são conduzidas será responsável pelos seus resultados" (FREITAS et al., 1997).

Há alguns anos poderíamos dizer que as empresas só provocavam mudanças em seus processos quando passavam por momentos de crise, perdendo dinheiro ou tornando-se obsoletas. Mas atualmente todas as empresas, inclusive, as líderes no mercado precisam mudar e melhorar continuamente para manter sua competitividade, e para que tudo isso ocorra, se faz necessário uma grande reestrutura organizacional, onde todos possam falar a mesma língua. "Os conceitos de qualidade, satisfação do cliente e excelência mudaram muito. E continuam mudando. Hoje, nenhum deles é suficiente. É preciso ultrapassá-los e melhorálos continuamente" (MARIOTTI, 1999).

Segundo Gouillart (1995) as empresas estão permanentemente enfrentando desafios para se adaptar a mudanças em seu meio ambiente, mudanças nas atitudes dos clientes e dos órgãos reguladores e sinais de extinção de seus ramos de atuação. Herzog (1991) afirma que mudança no contexto organizacional engloba alterações fundamentais no comportamento humano, dos padrões de trabalho e nos valores em resposta a modificações ou antecipando alterações estratégicas, de recursos ou de tecnologia.

Para Lewin (1984), a mudança cultural precisa penetrar em todos os aspectos da vida, ao mesmo tempo que deve se manifestar como sendo mudança de atmosfera cultural, não sendo apenas uma mudança de itens isolados. Para efetuar qualquer mudança é necessário perturbar o equilíbrio entre as forças que mantêm em determinado nível a auto regulação social. Trata-se de um processo em que as mudanças de conhecimento e crenças, as de valores e padrões, as de ligações e necessidades emocionais e mudanças de conduta cotidiana não ocorrem aos poucos e independentemente uma das outras, mas dentro do quadro de vida total do indivíduo no grupo.

\section{Conscientização e a Importância de Adquirir uma Certificação}

As organizações com o passar dos anos, observaram que o acesso a certificação de qualidade dos produtos, serviços e processos, deixariam as mesmas com alta performance e destaque no seguimento que atua. "A organização deve continuamente, melhorar a eficácia do sistema de gestão da qualidade por meio do uso da política da qualidade, objetivos da qualidade, resultados de auditorias, análise de dados, ações corretivas e preventivas e análise crítica pela direção" (ISO 9001:2008). 
A certificação ISO 9001:2008, agrega valor do produto ou serviço certificado, não só para empresa, mas também ao governo e toda a sociedade, uma vez que mostra que determinada região do país tem um desenvolvimento maior e melhor no quesito gestão da qualidade. Tudo isso abre as portas do comércio internacional para as empresas que tem a mentalidade de expansão dos negócios.

Quando uma organização consegue manter todos os seus colaboradores focados e comprometidos com a qualidade de todos os processos, o sucesso profissional se torna mais fácil de ser alcançado, pois todos estarão concentrados em um objetivo comum que satisfaz a todos na mesma proporção.

\section{Requisitos Gerais da ISO 9001: 2008}

A organização deve estabelecer, documentar, implementar e manter um sistema de gestão da qualidade e melhorar continuamente a sua eficácia de acordo com os requisitos da norma ISO 9001:2008.

A organização deve: Determinar os processos necessários para o sistema de gestão da qualidade e sua aplicação por toda a organização; Determinar a sequência e interação desses processos; determinar critérios em métodos necessários para assegurar que a operação e o controle desses processos sejam eficazes; assegurar a disponibilidade de recursos e informações necessárias para apoiar a operação e o monitoramento desses processos; monitorar, medir onde aplicável e analisar esses processos e implementar ações necessárias para atingir os resultados planejados e a melhoria contínua desses processos. Esses processos devem ser gerenciados pela organização de acordo com os requisitos da norma. (ISO:9001, 2008)

No momento em que uma organização decide implantar de fato a certificação desejada, todos os colaboradores já deverão estar imbuídos do processo, sabendo o porquê, quando e como será feito esta implantação. Com todos informados, começa o momento de colocar os procedimentos de implantação em prática. Vale salientar que é um tralho árduo, pois todos os setores da organização deverão estar trabalhando de forma padronizada e isso levará a erros e acertos constantes.

\section{Pontos Positivos e Negativos da Implementação da Certificação ISO: 9001:2008}

A certificação ISO 9001/2008 é adequada para qualquer organização que busca melhorar a forma de como executa o seu trabalho e como é gerenciada, independentemente de tamanho e setor. Entretanto, os melhores resultados sobre os investimentos são obtidos pelas companhias que estão preparadas para implementá-la em toda a sua organização. Ao invés de fazer em alguns locais, divisões ou apenas em alguns departamentos (LÉLIS, 2012). A ISO 9001/2008, trabalha com foco amplo na sua norma e prioriza as expectativas e necessidades de todo o seu público.

Observa-se que implantação da certificação da qualidade, traz um leque de pontos positivos citados cima, onde a organização passa a ser vista com outros olhos, onde a concorrência terá o receio de estar disputando espaço no mercado, com uma empresa que pensa a frente das necessidades do público consumidor. Ainda sobre pontos positivos e negativos, Silva et al.. (2014) afirma que é possível encontrar nas organizações certificadas com a ISO 9001 
Os pontos negativos são os seguintes: (a) Um sistema pouco flexível; (b) Não assegura melhoria do serviço; (c) Os objetivos não ficam claramente definidos, podendo obter a certificação e oferecer um produto de má qualidade; (d) Implica burocracia excessiva a partir da exigência de muitos papéis e documentos.

Os pontos positivos são os seguintes: (a) É mais fácil aplicar o conceito de melhoria contínua; (b) Tem mais repercussão no mercado internacional, melhorando a imagem e prestígio; (c) Ordena e organiza os procedimentos, as normas e as tarefas; (d) Obriga a manter o sistema mediante evoluções contínuas.

\section{Reação dos Clientes após Implementação da ISO 9001:2008}

Os clientes possuem uma visão crítica sobre o conceito de qualidade, pois os mesmos se tornam cada vez mais exigentes diante das ofertas das mercado. Os consumidores consideram alguns itens relevantes quando efetuam a aquisição de algo numa empresa certificada. A qualidade deverá sempre estar no produto ou serviço de forma que surpreenda as expectativas do mesmo, o preço também deverá estar acessível, variedades de opções de escolha e de apresentação.

Este entendimento conduz ao conceito da qualidade enquanto multiplicidade de itens. Segundo este conceito, um consumidor nunca escolhe um bem de consumo ou um serviço por um único aspecto, mas por um conjunto de razões. Simultaneamente, as razões que determinam a um consumidor adquirir um carro não são as mesmas que induzem outro consumidor a comprar o mesmo carro. (PALADINI, 2009)

\section{Fidelização Dos Clientes Pelos Processos Organizacionais}

A fidelização dos clientes a partir do momento da aquisição da certificação ISO 9001/2008, não se dará de forma repentina e sim de forma paulatina. Trata-se de um trabalho de persistência e de quebra de paradigmas que os clientes criaram ao longo do tempo. Por isso o fator persistência deverá estar latente em todos os colaboradores da organização, desde o nível operacional ao estratégico.

É evidente que a fidelidade do consumidor não ocorre de forma abrupta. Trata-se de uma conquista lenta, gradativa, crescente, cuidadosa, que só vai se tornando consistente aos poucos. Requer o entendimento da perspectiva dinâmica do mercado; exige o permanente acompanhamento de suas características e a análise precisa das tendências, das mudanças ou das alterações de rumo que vão se processando no ambiente externo à organização. É, essencialmente, uma ação evolutiva, que se materializa por uma crescente proximidade da organização aos mercados a que ela pretende atender. (PALADINI, 2009)

De acordo com os dados obtidos nas plataformas do sítio do Instituto Nacional de Metrologia, Qualidade e Tecnologia - INMETRO, foi possível ver que aos poucos os estados das federações estão tendo um crescente na qualidade dos processos e isso faz com que tenham uma maior visibilidade no cenário de prestação de serviço, limpeza e manutenção predial.

Tabela 01: Números de certificados por Estado da federação.

\begin{tabular}{|l|l|}
\hline ESTADO & CERTIFICADOS EMITIDOS \\
\hline São Paulo & 12996 \\
\hline Minas Gerais & 1454 \\
\hline Paraná & 1416 \\
\hline Rio de Janeiro & 1213 \\
\hline Santa Catarina & 964 \\
\hline Rio Grande do Sul & 639 \\
\hline Amazonas & 534 \\
\hline
\end{tabular}




\begin{tabular}{|l|l|}
\hline Bahia & 428 \\
\hline Pernambuco & 343 \\
\hline Espírito Santo & 376 \\
\hline Goiás & 170 \\
\hline Ceará & 93 \\
\hline Distrito Federal & 198 \\
\hline Pará & 78 \\
\hline Alagoas & 101 \\
\hline Rio Grande do Norte & 87 \\
\hline Maranhão & 41 \\
\hline Mato Grosso & 72 \\
\hline Sergipe & 79 \\
\hline Mato Grosso do Sul & 95 \\
\hline Paraíba & 40 \\
\hline Piauí & 32 \\
\hline Tocantins & 50 \\
\hline Acre & 53 \\
\hline Rondônia & 35 \\
\hline Roraima & 05 \\
\hline Amapá & 00 \\
\hline
\end{tabular}

Fonte: INMETRO (2017).

\section{CONCLUSÃO}

Após análise das informações deste artigo científico, obtidas através de pesquisas bibliográficas, concluiu-se que um dos fatores de maior relevância nos impactos da implantação da ISO 9001/2008, tratase da relutância em mudança de comportamento e atitude dos clientes internos, onde os mesmos estão habituados a realizarem a mesma atividade, da mesma forma durante anos que laboram nas organizações, negando-se a construção de novos paradigmas.

Os impactos positivos descritos nesta pesquisa sobressaíram os negativos, sendo evidenciado que a gestão da qualidade nas organizações que vendem produtos ou serviços, sempre trará bons resultados sociais, de qualidade e financeiros. Por mais que a implantação do sistema de gestão da qualidade seja árdua, o retorno a médio e longo prazo, mostrará que todo o empenho da organização foi de grande valia, isso representado através de maior número de clientes em seu portfólio, visibilidade positiva diante a sociedade e fidelização de clientes.

A implantação do manual da qualidade em uma empresa promove a universalização e padronização das ações e processos, onde todo e qualquer colaborador estará apto a solucionar as demandas internas e externas no seu ambiente de trabalho, extinguindo as não conformidades encontradas nos processos e quando não possível atenuando as mesmas.

Esse trabalho objetiva analisar os impactos causados no processo de implantação da ISO 9001/2008 nas empresas prestadoras de serviços em limpeza e manutenção predial, identificando as principais mudanças no comportamento organizacional e descrevendo os seus passos de implementação da certificação. A verificação da reação dos colaboradores diante das mudanças dos processos internos e externos, faz com que esse trabalho seja de tamanha relevância, pois relata os motivos internos e externos da organização em se conscientizar da importância de aquisição de uma certificação da qualidade. 


\section{REFERÊNCIAS}

ABNT. NBR ISO 9001:2008. 2 ed. Sistemas de gestão da qualidade: Requisitos. Rio de Janeiro: ABNT, 2008.

AL-RAWAHI, A.. On the implementation of ISO 9001:2000: a comparative investigation. The TQM Journal, v.23, n.6, p.683-687, 2011.

BARÇANTE, L. C.. Qualidade total: uma visão brasileira: o impacto estratégico na universidade e na empresa. Rio de Janeiro: Campus, 1998.

CARVALHO, M. M.; PALADINI, E. P.. Gestão da qualidade: teoria e casos. 2 ed. Rio de Janeiro: Elsevier, 2012.

CROSBY, P.B.. Qualidade é investimento. Rio de Janeiro: José Olympio, 1994.

FEIGENBAUM, A. V.. Total quality control. 3 ed. Singapore: McGraw-Hill, 1983.

FREITAS, H.. Informação e decisão: sistemas de apoio e seu impacto. Porto alegre: Ortiz, 1997.

GOUILLART, F. J.; KELLY, J. N.. Transformando a

Organização. São Paulo: Makron Books, 1995.

HERZOG, J. P. People: the critical factor in managing people. Journal of Systems Management, Clevaland, v.42, n.3, p.6$11,1991$.

IBGE. Estatísticas do Cadastro Central de Empresas. 2017.

ISO. International Standard Organization. The ISO Survey of Management System Standard Certifications. 2011.

ISHIKAWA, K.. TQC: estratégia e administração da qualidade. São Paulo: IM\&C, 1986.

JURAN, J. M.. Quality control handbook. 4 ed. Singapore: McGraw-Hill, 1988.

KOTLER, P.; KELLER, K. L.. Administração de marketing. 14 ed. São Paulo: Pearson Education do Brasil, 2012.
LÉLIS, E. C.. Gestão da qualidade. São Paulo: Pearson Prentice Hall, 2012.

LEWIN, K.. Problemas de dinâmica de grupo. São Paulo: Cultrix, 1984

MARIOTTI, H.. Organizações de Aprendizagem. 2 ed. São Paulo: Atlas, 1999.

MARSHALL JÚNIOR, I.. Gestão da Qualidade. 10 ed. Rio de Janeiro: FGV, 2010.

OLIVEIRA, O. J.. Gestão da Qualidade: Introdução à História e Fundamentos. In: OLIVEIRA, O. J.. Gestão da Qualidade: Tópicos Avançados, 2012.

PALADINI, E. P.. Gestão da qualidade: Teoria e prática. 3. Ed., São Paulo: Atlas, 2012.

PALADINI, E. P.. Gestão da qualidade: teoria e prática. 2a edição. São Paulo: Atlas, 2009.

PALADINI, E. P.. Gestão da qualidade: teoria e prática. São Paulo: Atlas, 2000.

SANTOS, S. B.. Certificação ISO 9001/2000: uma avaliação sobre o processo de implementação no IV juizado especial cível do Tribunal de Justiça do Estado do Rio de Janeiro. Dissertação (Mestrado) - Universidade Federal do Rio de Janeiro, Rio de Janeiro, 2007.

SILVA, F. A. B.. Géstion de certicacación de calidad como fator de competitividaden el sector industrial de manufactura, em la région transfronteriza. Revista Internacional Administración e Finanzas, v.7, n.1, 2014.

VERGUEIRO, W.. Qualidade de Serviços. 4 ed. São Paulo: Atlas, 2002.

VERGARA, S. C.. Projetos e relatórios de pesquisa em administração. 13 ed. São Paulo: Atlas, 2011.

ZACHARIAS, O. J.. ISO 9001:2008: uma ferramenta de gestão empresarial. São Paulo: 2009. 